\title{
Sistem Informasi Sentra Pelayanan Kepolisian Terpadu (SPKT) Polsek Jajaran di Polresta Surakarta
}

\author{
Erni Widarti*1, Agung Koes Indarto ${ }^{2}$, Aditya Primahardika ${ }^{3}$ \\ ${ }^{1,2}$ Program Studi Sistem Komputer; STMIK AUB, Surakarta, Indonesia \\ ${ }^{3}$ Program Studi Sistem Informasi, STMIK AUB, Surakarta, Indonesia \\ e-mail: *1erni.widarti@s tmik-aub.ac.id, ${ }^{2}$ aindarto@stmik-aub.ac.id
}

\begin{abstract}
Abstrak
POLRI merupakan salah satu instansi yang menggelar pelayanan publik kepada masyarakat.Satuan POLRI di wilayah Kota Surakarta adalah Polresta Surakarta yang mempunyai satuan tingkat dibawahnya yaitu Polsekyang berjumlah 5 Satuan Polsek. Salah satu fungsi yang ada di Polresta Surakarta maupun Polsek jajarannya adalah Sentra Pelayanan Kepolisian Terpadu (SPKT) yang bertugas memberi pelayanan berupa penerimaan laporan.

Penerimaan laporan dan pengolahan data di SPKT Jajaran Polsek di Polresta Surakarta dan Polsek jajarannya masih dilakukan secara manual seperti pembuatan laporan menggunakan Microsoft Office Word dalam pembuatan laporan sehingga melakukan penumpukan file dan pengetikan yang berulang-ulang, dan dalam memberi nomor register maupun melakukan perekapan masih menggunakan cara manual.

Dengan melakukan penelitian di SPKT di Polresta Surakarta dan Polsek jajarannya penulis berfikir untuk membuat Sistem Informasi. Dalam penelitian ini, Metode pengembangan sistem yang digunakan adalah waterfall model dengan langkah analisis kebutuhan sistem, perancangan sistem, penulisan kode program, pengujian dengan metode blackbox, implementasi dan pemeliharaan. Sistem yang dibangun menggunakan Microsoft Visual Basic.net 2013 sebagai tool pengembangan perangkat lunak (development tool), bahasa pemrograman Visual Basic dan MySQL sebagai DBMS nya yang dibuat online atau cloud database.

Sistem Informasi Sentra Pelayanan Kepolisian di Polresta Surakarta dapat menjadi salah satu solusi yang dapat digunakan untuk mempermudah petugas dalam menerima setiap laporan yang masuk dari masyarakat. Menyediakan interface yang dapat mempermudah petugas dalam melakukan pencarian data atau laporan.
\end{abstract}

Kata kunci-Sistem Informasi, SPKT, Polresta Surakarta, Polsek, Database Digital, MySQL, Visual Basic.Net

\section{Abstract}

POLRI is one of the institutions that hold public services to the public. POLRI Unit in the Surakarta City is Polresta Surakarta which has a lower level unit that is Polsek numbering 5 units of Polsek. One of the functions that exist in Surakarta Police and Police officers is the Integrated Police Service Center (SPKT) which is in charge of providing services in the form of acceptance reports.

Receipt of reports and data processing in SPKT Polsek ranks in Polresta Surakarta and Polsek ranks are still done manually such as making reports using Microsoft Office Word in the making of reports so do the repeated accumulation of files and typing, and in giving the register number and do the recording still use manual way. 
By doing research in SPKT in Polresta Surakarta and Polsek ranks writer think to make Information System. In this research, system development method used is waterfall mo del with step analysis system requirement, system design, writing program code, testing with blackbox method, implementation and maintenance. The system is built using Microsoft Visual Basic.net 2013 as a software development tool (development tool), Visual Basic programming language and MySQL as its DBMS is made online or cloud database.

Police Information Center Information System in Surakarta Polresta can be one solution that can be used to facilitate the officer in receiving every report coming from the co mmu nity. Provides an interface that can facilitate officers in searching data or reports.

Keywords - Information System, SPKT, Surakarta Police, Polsek, Database Digital, MySQL, Visual Basic .Net

\section{PENDAHULUAN}

Pelayanan publik tidak terlepas dari masalah kepentingan umum, yang menjadi asalusul timbulnya istilah pelayanan publik. Pelayanan publik adalah pemenuhan keinginan dan kebutuhan masyarakat oleh penyelenggara negara dan negara didirikan oleh publik dengan tujuan agar dapat meningkatkan kesejahteraan masyarakat (Sinambela, 2011).

Salah satu instansi yang menerapkan pelayanan publik adalah Kepolisian Republik Indonesia (POLRI). Sesuai dengan Undang - Undang Nomor 2 Tahun 2002 tentang Kepolisian Negara Republik Indonesia, tugas Kepolisian adalah melindungi, melayani dan mengayomi masyarakat serta melakukan penegakan hukum. Tugas tersebut dilaksanakan mulai dari tingkat paling atas/Markas Besar (MABES) hingga kesatuan paling kecil yaitu tingkat Kepolisian Sektor (POLSEK). Salah satu unit atau fungsi yang terdapat di POLRI adalah Sentra Pelayanan Kepolisian Terpadu (SPKT) merupakan unit pelayanan Kepolisian yang disiagakan dan ditempatkan oleh POLRI, dari tingkat wilayah hukum terkecil POLRI yaitu Polsek sampai tingkat pusat yaitu Markas Besar dan ada di seluruh wilayah Republik Indonesia. Dengan fungsi utama memberi pelayanan Kepolisian kepada masyarakat yang membutuhkan, dalam bentuk penerimaan dan penanganan pertama laporan atau pengaduan dari masyarakat seperti Laporan adanya tindak pidana, laporan kehilangan, laporan adanya suatu kejadian maupun bencana, permintaan bantuan Kepolisian dan penyelesaian perselisihan antar warga.

Kepolisian Resor Kota Surakarta (POLRESTA SURAKARTA) sebagai mana kesatuan tingkat Kota Surakarta juga mempunyai tugas memberikan pelayanan kepada masyarakat. Dimana pada Polresta Surakarta terdapat lima Satuan wilayah dibawahnya atau yang disebut Polsek, yaitu : Polsek Laweyan, Polsek Banjarsari, Polsek Serengan, Polsek Pasar Kliwon dan Polsek Jebres. Polsek sebagai ujung tombak satuan POLRI menjadi tumpuan terdepan dalam kegiatan pelayanan Kepolisan. Dimana semua laporan yang masuk pada Sentra Pelayanan Kepolisian Terpadu akan di olah untuk menjadi acuan pimpinan dalam mengambil atau membuat kebijakan.

Setelah penulis mempelajari dan mengamati kegiatan di Sentra Pelayanan Kepolisian Terpadu yang terdapat pada jararan Polsek di Polresta Surakarta masih menggunakan cara manual dalam pembuatan laporan polisi seperti saat pemberian nomor registrasi laporan polisi harus melihat nomor terakhir di buku register yang ada. begitu juga dalam pembuatan laporan dimana pembuatannya dilakukan dengan cara menumpuk atau menghapus laporan yang lama untuk membuat laporan yang baru. Hal ini dapat memperlama pekerjaan anggota polisi dan mengakibatkan penyampaian informasi kepada pimpinan ataupun kepada satuan atas yaitu dari Polsek ke Polres menjadi lebih lambat.

Melihat kegiatan di Sentra Pelayanan Kepolisian Terpadu penulisberfikir alangkah lebih baiknya dibuat suatu sistem yang dapat mempermudah dan mempercepat pekerjaan anggota Sentra Pelayanan Kepolisian Terpadu sehingga pelayanan yang diberikan kepada masyarakat juga dapat lebih meningkat, serta dapat mempercepat pengolahan dan penyampaian informasi kepada atasan. Dengan dibuatnya sistem maka akan ada database digital sebagai backup atau 
cadangan apabila ada kerusakan atau kehilangan arsip, pada pembuatan laporan polisi dan penomoran juga akan lebih tertata dan teratur. Adanya sistem juga akan membantu dalam pengolahan data yang masuk sehingga mempermudah evaluasi kinerja dengan melihat statistik yang ada.

\section{METODE PENELITIAN}

Pada metode penelitian menjelaskan metode apa yang digunakan dalam penelitian meliputi pengumpulan data, jenis sumber data, pengembangan sistem dan pengujian sistem.

\subsection{Metode Pengumpulan Data}

Pengumpulan data yang digunakan dalam penelitian ini meliputi observasi, wawancara, tinjauan pustaka.

\subsubsection{Observasi}

Metode observasi merupakan metode pengumpul data yang dilakukan dengan cara mengamati dan mencatat secara sistematik gejala-gejala yang diselidiki (Supardi, 2006). Observasi dilakukan menurut prosedur dan aturan tertentu sehingga dapat diulangi kembali oleh penulis dan hasil observasi memberikan kemungkinan untuk ditafsirkan secara ilmiah. Pada metode ini, penulis melakukan observasi langsung ke Polresta Surakarta guna memperoleh data yang akan dikelola oleh penulis.

\subsubsection{Wawancara}

Metode wawancara (disebut pula interview) adalah cara pengumpulan data yang dilakukan melalui percakapan antara penulis (atau orang yang ditugasi) dengan subyek penelitian atau responden atau sumber data (Budiyono, 2000). Pada metode ini, penulis secara bertatap muka mewawancari angggota Sentra Pelayanan Kepolisian di jajaran Polsek maupun di Polresta Surakarta guna mendapatkan data yang diperlukan oleh penulis

\subsubsection{Tinjauan pustaka}

Metode Pustaka melibatkan beberapa dokumen. Pengertian dari kata dokumen menurut (Gottschalk, 1986) seringkali digunakan para ahli dalam dua pengertian, yaitu pertama, berarti sumber tertulis bagi informasi sejarah sebagai kebalikan daripada kesaksian lisan, artefak, peninggalan-peninggalan terlukis, dan petilasan-petilasan arkeologis. Pengertian kedua, diperuntukan bagi surat-surat resmi dan surat-surat negara seperti surat perjanjian, undangundang, hibah, konsesi, dan lainnya. Lebih lanjut, Gottschalk menyatakan bahwa dokumen (dokumentasi) dalam pengertianya yang lebih luas berupa setiap proses pembuktian yang didasarkan atas jenis sumber apapun, baik itu yang berupa tulisan, lisan, gambaran, atau arkeologis.

Menurut Usman dan Akbar (2000) metode ini juga dilakukan dengan cara membaca atau mempelajari buku-buku referensi literature yang berhubungan dengan masalah yang akan dibahas guna memperoleh landasan teori untuk keperluan menganalisa data.

\subsection{Jenis Sumber Data}

Jenis data dan sumber data yang digunakan dalam penelitian ini antara laian data promer dan data sekunder.

\subsubsection{Data Primer}

Data primer merupakan data yang diperoleh secara langsung dari obyek penelitian. Data primer yang diperoleh berupa informasi proses pelaporan dan jenis laporan polisi di Sentra Pelayanan kepolisian Polresta Surakarta dan jajaran Polsek di jajaran Polresta Surakarta. 


\subsubsection{Data sekunder}

Data sekunder merupakan data yang diperoleh secara tidak langsung dari obyek penelitian seperti yang diperoleh dari membaca buku-buku, literatur, artikel yang berhubungan dengan penelitian.

\subsection{Metode Pengembangan Sistem}

Model Air Terjun ini adalah model yang dikembangkan untuk pengembangan perangkat lunak, membuat perangkat lunak. model berkembang secara sistematis dari satu tahap ke tahap lain dalam mode seperti air terjun. Model pengembangan ini bersifat linear dari tahap awal pengembangan sistem yaitu tahap perencanaan sampai tahap akhir pengembangan sistem yaitu tahap pemeliharaan. Tahapan berikutnya tidak akan dilaksanakan sebelum tahapan sebelumnya selesai dilaksanakan dan tidak bisa kembali atau mengulang ke tahap sebelumnya.

Metode pengembangan sistem air terjun (waterfall) adalah sebuah proses perencanaan, dimana semua proses kegiatan harus terlebih dahulu direncanakan dan dijadwalkan sebelum dikerjakan (Sommerville, 2011). Metode Waterfall dapat dilihat pada Gambar 1, dimana metode pengembangan perangkat lunak yang mengusulkan pendekatan kepada perangkat lunak sistematik dan sekuensial yang mulai pada tingkat kemajuan sistem pada seluruh analisis, desain, kode, pengujian dan pemeliharaan.

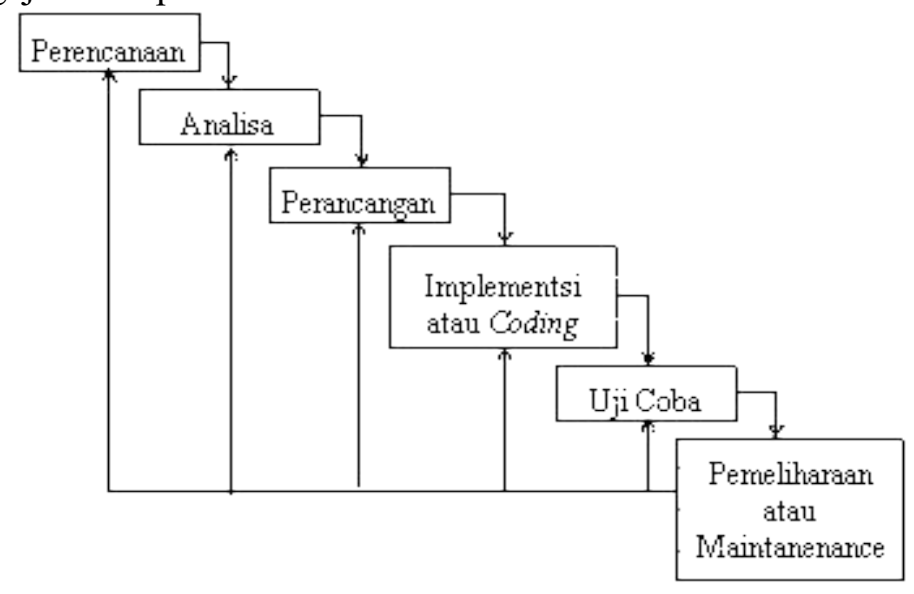

Gambar 1 Model Waterfall (Pressman, 2010)

\subsection{Metode pengujian sistem}

Metode PIECES adalah metode analisis sebagai dasar untuk memperoleh pokok-pokok permasalahan yang lebih spesifik. Dalam menganalisis sebuah sistem, biasanya akan dilakukan terhadap beberapa aspek antara lain adalah kinerja, informasi, ekonomi, keamanan aplikasi, efisiensi dan pelayanan pelanggan (Ragil, 2010). Analisis ini disebut dengan PIECES Analysis. Untuk mengetahui kelemahan sistem maka penulis menggunakan metode analisa kelemahan sistem yang dikenal dengan metode PIECES yang terdiri dari enam aspek, yaitu:
a. Analisis Kinerja (Performance)
b. Analisis Informasi (Information)
c. Analisis Ekonomi (Economic)
d. Analisis Kontrol (Control)
e. Analisis Efisiensi (Efficiency)
f. Analisis Pelayanan (Service) 


\section{HASIL DAN PEMBAHASAN}

\subsection{Implementasi}

Implementasi merupakan tahapan penerapan sebuah program dalam pembangunan sistem. Implementasi dibuat berdasarkan hasil analisis serta design yang terinci terhadap suatu sistem yang sedang berjalan. Program Sistem Informasi Pelayanan Di Sentra Pelayanan Kepolisian Terpadu (SPKT) jajaran Polsek di Polresta Surakarta terdiri dari tampilan beberapa menu dan Form yang berfungsi untuk memasukkan, mengubah, menghapus, mencari data atau informasi tentang proses pembuatan laporan polisi dan pelayanan yang ada di Sentra Pelayanan Kepolisian Terpadu.

\subsection{Pemasangan Sistem atau Instalasi Sistem}

Secara umum instalasi system adalah proses pemasangan suatu sistem ke dalam komputer. Langkah-langkah penginstalan dapat terdiri dari beberapa langkah yang harus dilakukan ketika sedang melakukan proses install. Dalam pemasangan sistem informasi SPKT membutuhkan beberapa software agar sistem dapat berjalan lancar, software tersebut antara la in sebagai berikut :

a. Xampp software.

b. ODBC Connector.

c. Crystal Report Runtime.

Cara penginstalan aplikasi atau Sistem Informasi Pelayanan di Sentra Pelayanan Kepolisian Terpadu (SPKT) Jajaran Polsek di Polresta Surakarta adalah sebagai berikut :

a. Copy aplikasi "Arsip.exe" pada folder D: larsip

b. Install software xampp, dan pastikan module Apache dan Mysql xampp dalam keadaan hidup dengan menyeting pada xampp control panel

c. Import database dengan nama 'bertkats_spkt.sql"

d. Install crystal report runtime

e. Install ODBC Connector

f. Lakukan konfigurasi pada odbc dengan merubah IP, username, password dan nama database yang telah di import sebelumnya

g. Jalankan aplikasi

\subsection{Pengujian Sistem}

Pengujian merupakan hal terpenting yang bertujuan untuk menemukan kesalahan atau kekurangan pada perangkat lunak yang akan diuji. Pengujian dilakukan untuk mengetahui perangkat lunak yang dibuat sudah memenuhi kriteria yang sesuai dengan tujuan perancangan perangkat lunak tersebut.

Pengujian dengan black box testing terfokus pada unit program, apakah memenuhi kebutuhan (requirement) yang disebutkan dalam spesifikasi. Pengujian Black Box digunakan untuk menguji kesalahan fungsi khusus dari perangkat lunak yang dirancang misalnya kesalahan interface, kesalahan dalam struktur data atau kesalahan akses database eksternal, kesalahan kinerja, kesalahan inisialisasi dan kesalahan lainnya yang ada hubungan dengan pengujian black box. Dengan adanya pengujian sistem ini, sehinggan saat user menggunakan sistem, sistem ini sudah siap dan berjalan dan berfungsi sebagaimana mestinya.

\subsection{Tampilan Sistem/Interface}

\subsubsection{Halaman Awal}

Halaman awal adalah tampilan awal pada saat kita memulai sistem, tekan file akan keluar halaman login. Masuk dengan username dan password sesuai hak akses yang ada. Halaman awal dapat dilihat pada Gambar 2. 


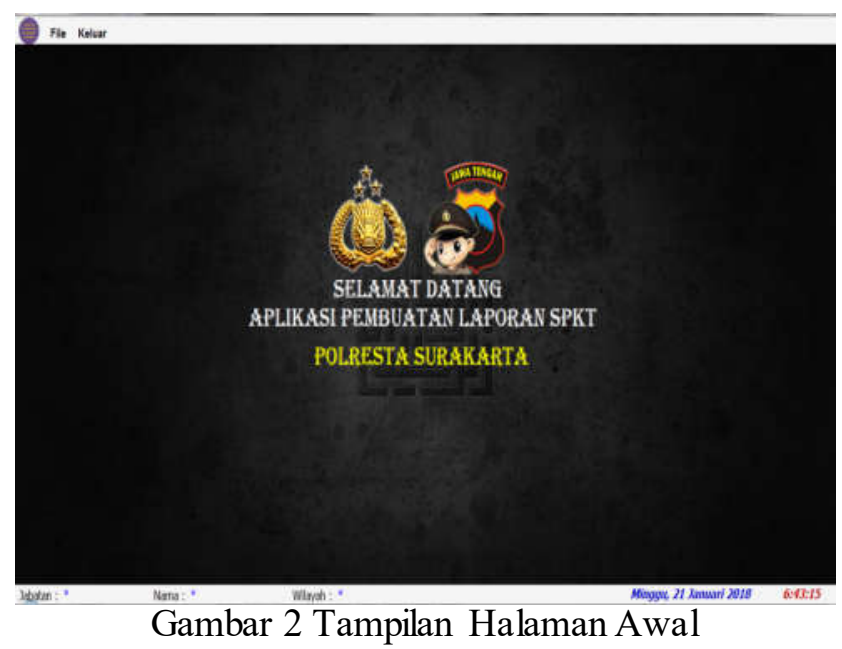

\subsubsection{Halaman Login}

Halaman login adalah halaman untuk masuk kedalam sistem dengan memasukan username dan password, terdapat dua hak akses untuk Polsek dan Polresta Surakarta saat melakukan login. Hak akses tersebut akan secara otomatis di seleksi oleh sistem. Halaman login dapat dilihat pada Gambar 3.

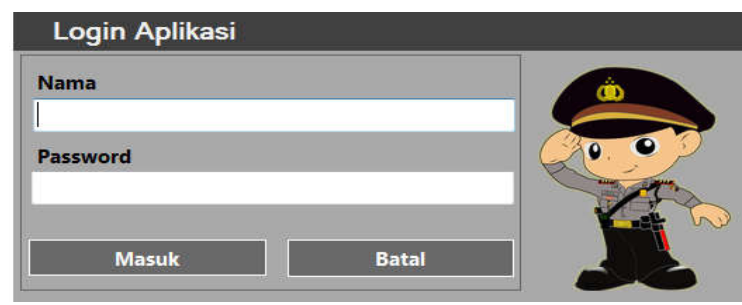

Gambar 3 Tampilan Halaman Login.

\subsubsection{Halaman Utama}

Halaman utama adalah halaman yang tampil setelah melakukan login sesuai dengan hak aksesnya. Dalam halaman ini ada beberapa menu yang bisa kita gunakan. Lingkaran pada kiri atas sebagai jalan pintas menu-menu yang sering digunakan, yaitu menu pembuatan laporan kehilangan, laporan polisi model A, laporan polisi model B dan pengantar dinsos. Untuk menu file terdapat dua pilihan yaitu $\log$ out untuk keluar dan petugas untuk mengelola petugas maupun user login yang ada. Menu rekap laporan digunakan untuk merekap laporan-laporan dalam jangka waktu tertentu. Menu lihat semua hanya ada pada aplikasi yang ada di Polresta, berguna untuk melihat semua laporan yang masuk di semua wilayah, baik laporan yang masuk di Polresta maupun dari Polsek-Polsek.

Ada perbedaan antara sistem yang ada di Polresta Surakarta dengan di jajaran Polsek, dimana sistem di Polresta Surakarta dapat melihat semua laporan yang masuk baik di Polsek dengan menggunkan menu lihat semua, sedangkan Polsek tidak dapat mengakses informasi atau melihat laporan pada Polsek yang lain. Halaman utama Polresta dapat dilihat pada Gambar 4 dan halaman utama Polsek dapat dilihat pada Gambar 5. 


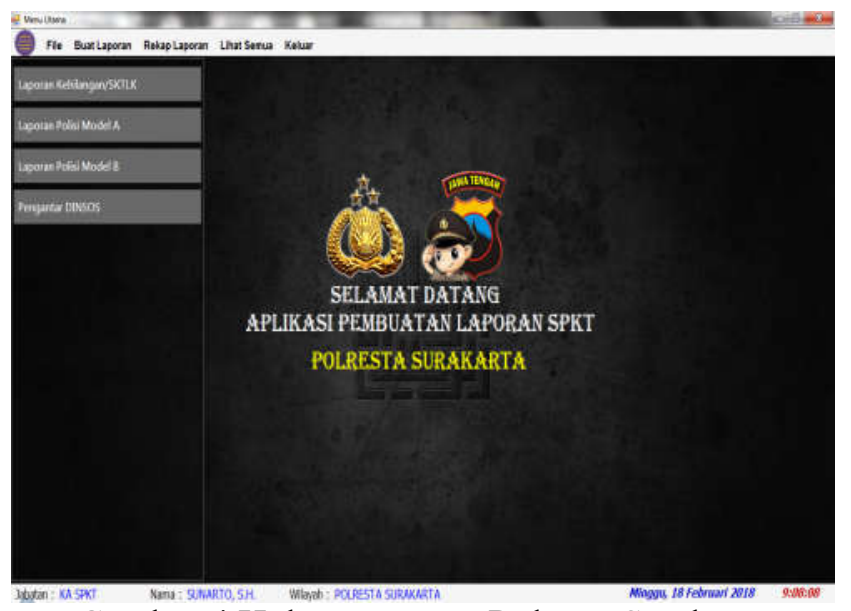

Gambar 4 Halaman utama Polresta Surakarta

Pada halaman utama Polresta Surakarta ini hanya dapat dibuka dengan hak akses sebagai Polresta Surakarta. Halaman ini kita dapat melihat hasil rekap dari semua wilayah Polsek di Polresta Surakarta.

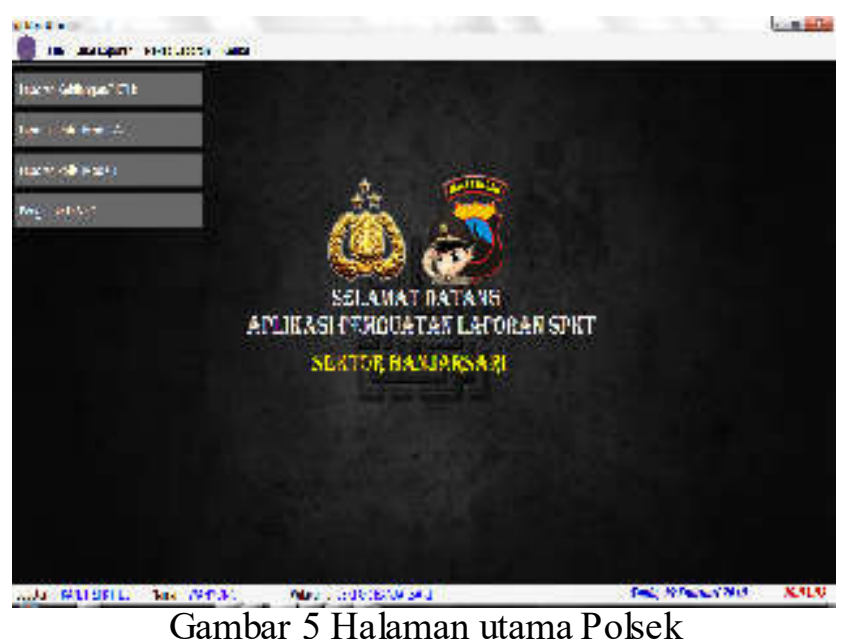

Pada halaman utama Jajaran Polsek ini hanya dapat dibuka dengan hak akses sebagai Polsek masing-masing. Halaman ini sama dengan halaman pada Polresta Surakarta hanya tidak dapat melihat hasil rekap dari Polsek yang lain maupun Polresta Surakarta.

\subsubsection{Menu laporan}

\subsubsection{Surat laporan kehilangan}

Halaman laporan kehilangan digunakan untuk membuat surat laporan kehilangan, dimana surat laporan kehilangan ini akan digunakan untuk membuat atau mencari surat-surat berharga yang telah hilang dan hanya berlaku selama empat belas hari. Pada halaman ini terdapat button tambah, hapus, bersihkan, print, keluar.

Dari beberapa fungsi tombol tersebut akan dijelaskan sebagai berikut, tombol tambah berguna untuk menambah laporan dengan otomatisasi nomor register laporan kehilangan, tombol hapus berguna untuk menghapus laporan yang tidak di inginkan, dan tombol bersihkan untuk membersihkan semua data yang ada. Tombol print berguna untuk mencetak laporan, untuk surat kehilangan akan di cetak sesuai keperluan yang dibutuhkan oleh pelapor.

Data petugas di gunakan untuk mengisi petugas yang menerima laporan dan Kepala Unit yang bertugas membubuhkan tanda tangan sebagai kewenangannya mengeluarkan laporan 
dan bertanggung jawab tentang laporan yang telah dibuat. Halaman laporan surat kehilangan dapat dilihat pada Gambar 6.

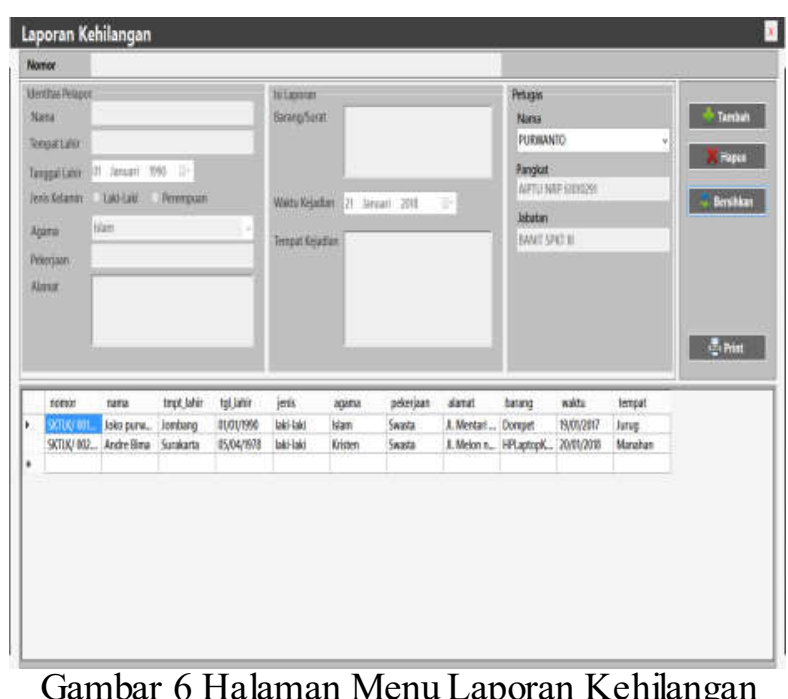

\subsubsection{Halaman Laporan Polisi A}

Halaman laporan polisi A digunakan untuk membuat surat laporan polisi model A. Halaman laporan polisi model A digunakan untuk membuat surat laporan polisi yang dimana pelapornya adalah anggota kepolisian, bisa berisi tindak pidana maupun kejadian yang ada. Dengan menekan button tambah pada nomor registrasi laporan polisi model A akan otomatis bertambah, sehingga operator atau petugas tidak perlu membuka buku nomor register laporan polisi model A.

Data petugas di gunakan untuk mengisi petugas yang menerima laporan dan Kepala Unit yang bertugas membubuhkan tanda tangan sebagai kewenangannya mengeluarkan laporan dan bertanggung jawab tentang laporan yang telah dibuat. Terdapat beberapa form yang harus di isi untuk melengkapi laporan polisi model A ini, antara lain : pelapor, terlapor, korban, saksi, peristiwa dan barang bukti. Setiap form akan dijelaskan lebih lanjut tentang cara penggunaan dan pemakaiannya. Apabila masih ada data yang belu di isi maka hasil cetak akan kosong semua, apabila tidak ada data bisa di tulis nihil atau di isi menggunakan tanda baca sambung. Untuk mencetak laporan menggunakan tombol LP A dengan simbol print. Halaman laporan polisi model A dapat dilihat pada Gambar 7.

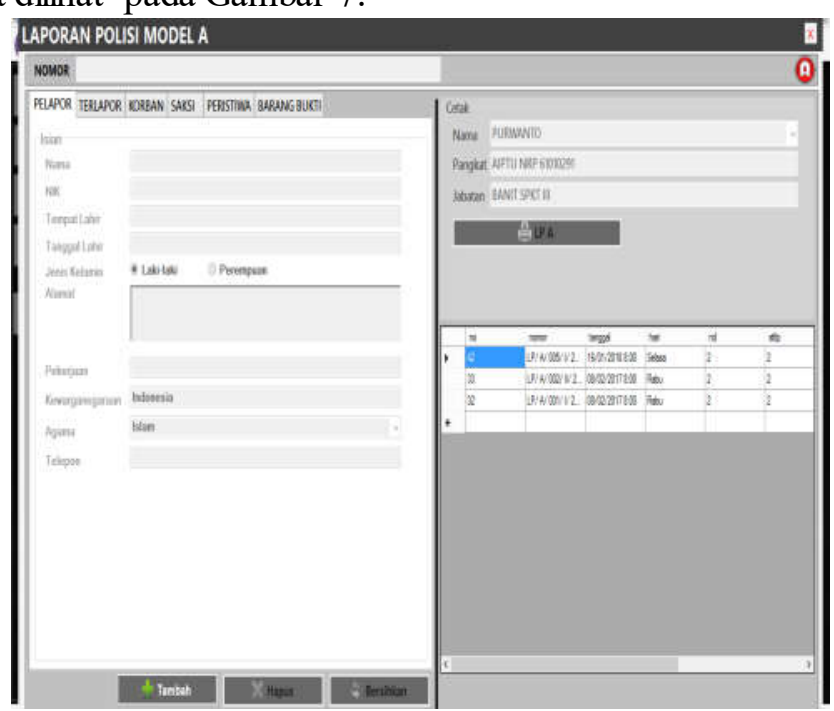

Gambar 7 Halaman Laporan Polisi Model A 


\subsubsection{Halaman Laporan Polisi B}

Halaman laporan polisi B digunakan untuk membuat surat laporan model B, yaitu laporan yang diterima dari masyarakat umum. Pada halaman laporan polisi model B kita bisa mencetak nota dinas, STTLP, surat keterangan, surat keterangan atau pernyataan dan rekomendasi yang akan digunakan oleh masyarakat untuk proses selanjutnya di Satuan Reserse. Hal ini akan sangat membantu petugas kepolisian karena tidak melakukan pengetikan ulang. Sehingga proses pelayanan kepada mastarakat akan berjalan lebih cepat dan optimal

Dengan menekan button tambah pada nomor registrasi laporan polisi model B akan otomatis bertambah, sehingga operator atau petugas tidak perlu membuka buku nomor register laporan polisi model B. Data petugas di gunakan untuk mengisi petugas yang menerima laporan dan Kepala Unit yang bertugas membubuhkan tanda tangan sebagai kewenangannya mengeluarkan laporan dan bertanggung jawab tentang laporan yang telah dibuat.

Terdapat beberapa form yang harus di isi untuk melengkapi laporan polisi model B ini, antara lain : pelapor, terlapor, korban, saksi, peristiwa dan barang bukti. Setiap form akan dijelaskan lebih lanjut tentang cara penggunaan dan pemakaiannya. Apabila masih ada data yang belum di isi maka hasil cetak akan kosong semua, apabila tidak ada data bisa di tulis nihil atau di isi menggunakan tanda baca sambung. Halaman laporan polisi model B dapat dilihat pada Gambar 8.

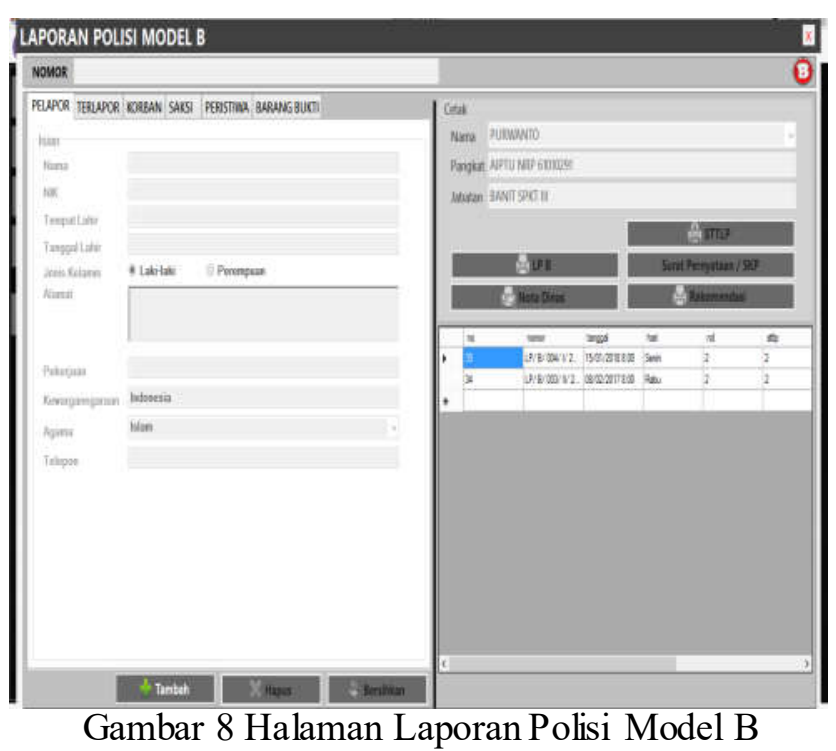

\subsubsection{Halaman Pengantar Dinas Sosial}

Halaman pengantar Dinas Sosial digunakan untuk membuat surat pengantar ke Dinas Sosial. Surat pengantar ini biasanya digunakan apabila ada masyarakat yang terlantar, kehabisan bekal, dll. Seperti contoh apabila ada masyarakat yang sedang melakukan perjalanan akan tetapi dompetnya jatuh, selain membuat surat kehilangan, maka bisa membuat surat ini dengan tujuan untuk melanjutkan perjalanan.

Terdapat beberapa form yang harus di isi untuk melengkapi Surat pengantar ini, antara lain : klasifikasi, pelapor, pengikut dan uraian. Setiap form akan dijelaskan lebih lanjut tentang cara penggunaan dan pemakaiannya. Apabila masih ada data yang belum di isi maka hasil cetak akan kosong semua, apabila tidak ada data bisa di tulis nihil atau di isi menggunakan tanda baca sambung.

Dengan menekan button tambah pada nomor registrasi surat pengantar dinas sosial akan otomatis bertambah, sehingga operator atau petugas tidak perlu membuka buku nomor register surat pengantar dinas sosial. Halaman form pengantar Dinsos dapat dilihat seperti pada Gambar 9. 


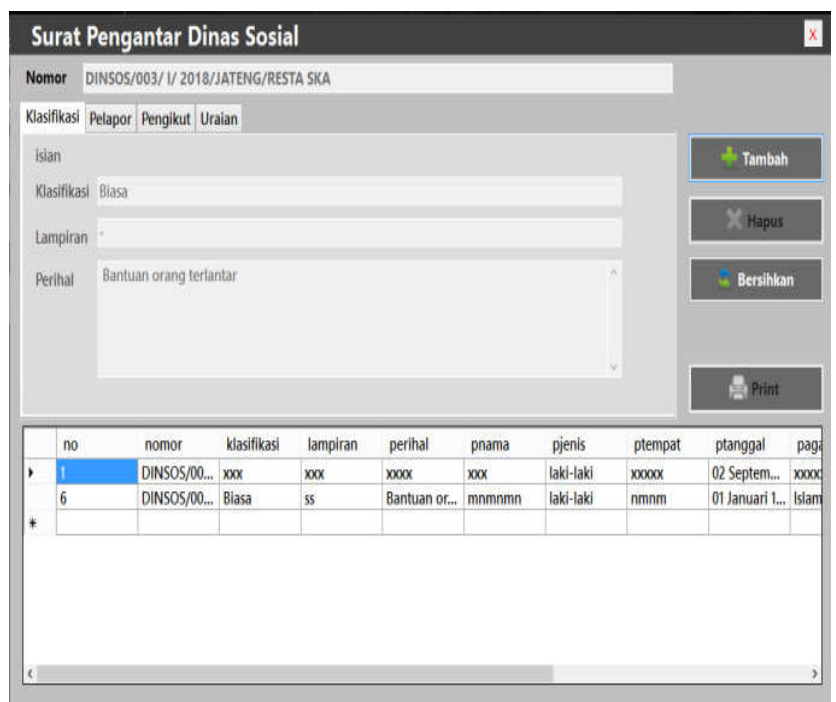

Gambar 9 Halaman Form Pengantar Dinas Sosial

\subsubsection{Menu Rekap Laporan}

Halaman cetak rekap digunakan untuk mencetak laporan polisi dalam rentang waktu tertentu, akan tetapi di Polresta Surakarta rekap kejadian atau laporan polisi adalah 1 x 24 jam sekali. Pada halaman ini, kita juga bisa merekap tiap laporan yang di inginkan seperti: rekap laporan kehilangan, rekap laporan polisi model A, rekap laporan polisi model B dan rekap surat pengantar Dinsos. Halaman rekap dapat dilihat seperti pada Gambar 10, gambar 11, gambar 12, gambar 13 dan gambar 14.

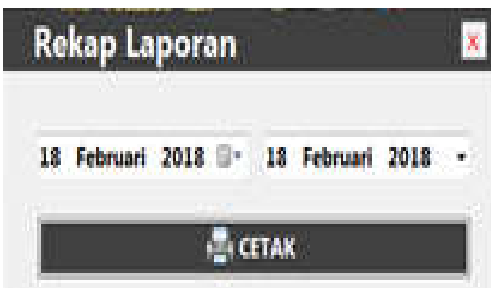

Gambar 10 Halaman Cetak Rekap Semua Laporan

Rekap Laporan Kehilangan

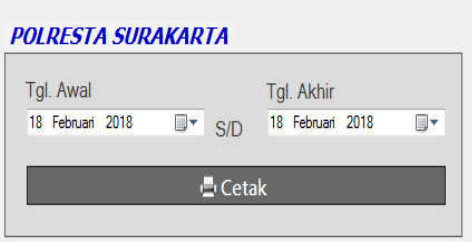

Gambar 11 Halaman Cetak Rekap Laporan Kehilangan

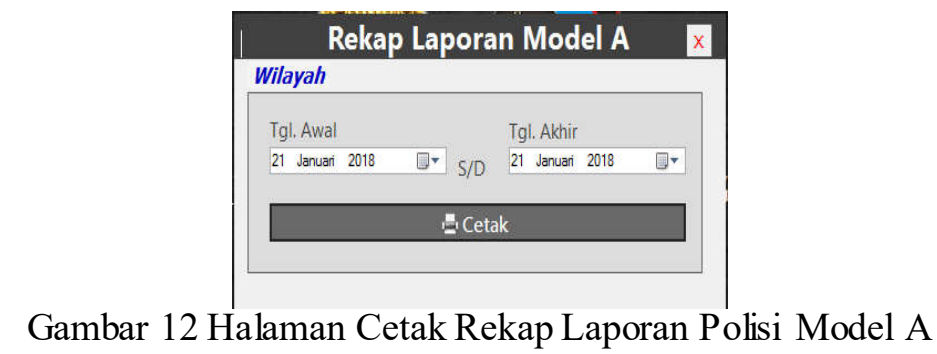




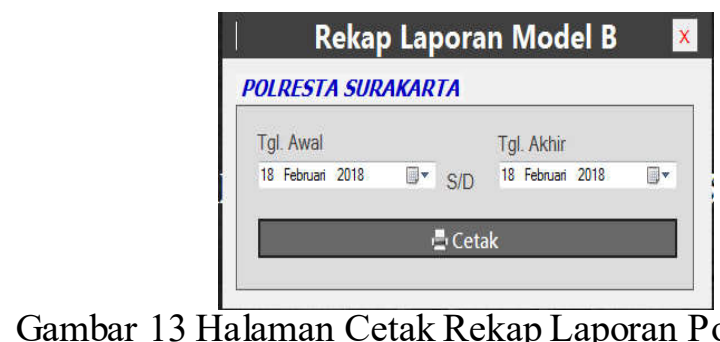

Gambar 13 Halaman Cetak Rekap Laporan Polisi Model B

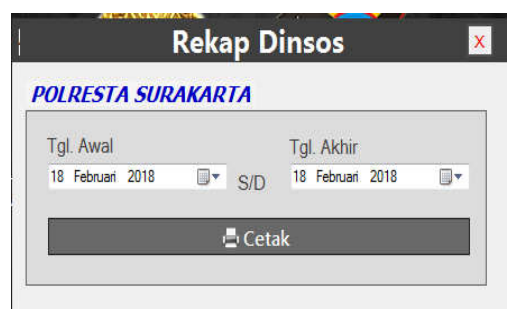

Gambar 14 Halaman Cetak Rekap Laporan Pengantar Dinsos

\subsubsection{6 Мепи Lihat sетиа}

Menu lihat semua hanya ada di sistem yang ada di Polresta Surakarta, sedangkan di jajaranPolsek tidak ada menu ini. Menu digunakan untuk melihat semua laporan yang ada di jajaran Polsek seperti pada Gambar 15. Kita bisa memilih jenis laporan dan wilayah yang ingin dilihat.

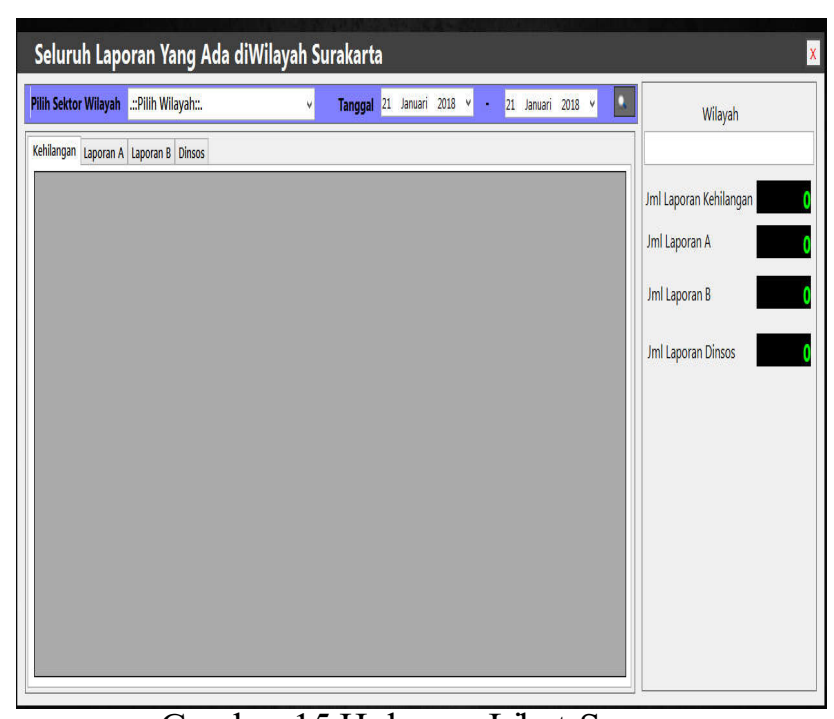

Gambar 15 Halaman Lihat Semua

\subsubsection{Menu Petugas}

Menu petugas digunakan untuk mengelola hak akses masuk login sistem, menentukan wilayah kerja, menentukan pejabat atau Kepala SPKT dan petugas operator. Pada halaman kepala SPKT berfungsi untuk membuat dan mengelola username dan password untuk masuk dalam sistem aplikasi, nama tersebut juga digunakan untuk menentukan pejabat yang berwenang mengeluarkan laporan maupun surat. Halaman operator berfungsi untuk membuat dan mengelola user atau operator penerima laporan. Nama Kepala SPKT dan operator akan otomatis muncul pada saat mencetak laporan. 


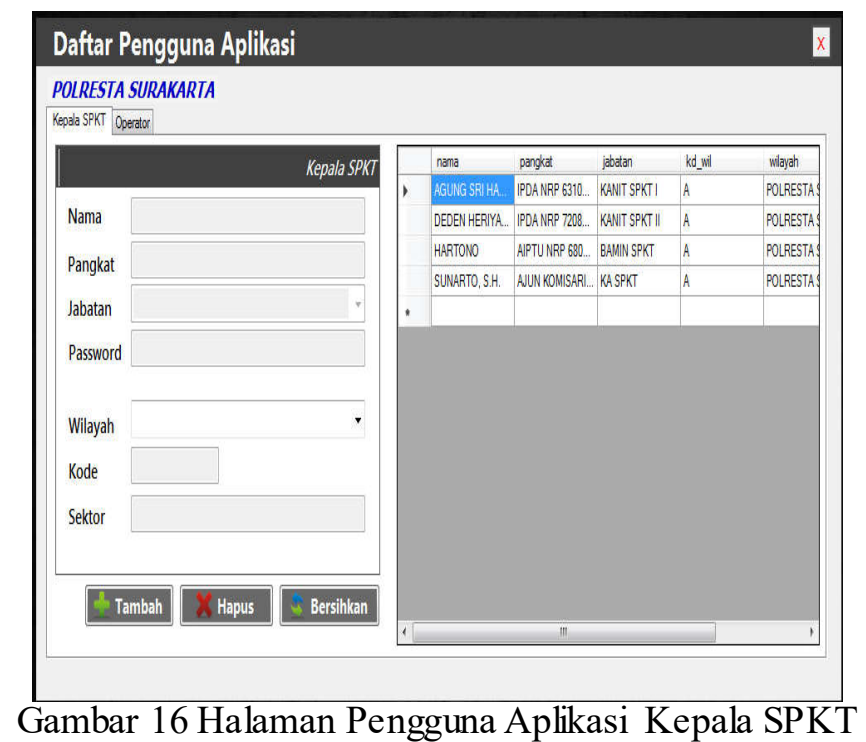

Halaman kepala SPKT seperti gambar 16 berfungsi untuk membuat dan mengelola username dan password untuk masuk dalam sistem aplikasi, nama tersebut juga digunakan untuk menentukan pejabat yang berwenang mengeluarkan laporan maupun surat.

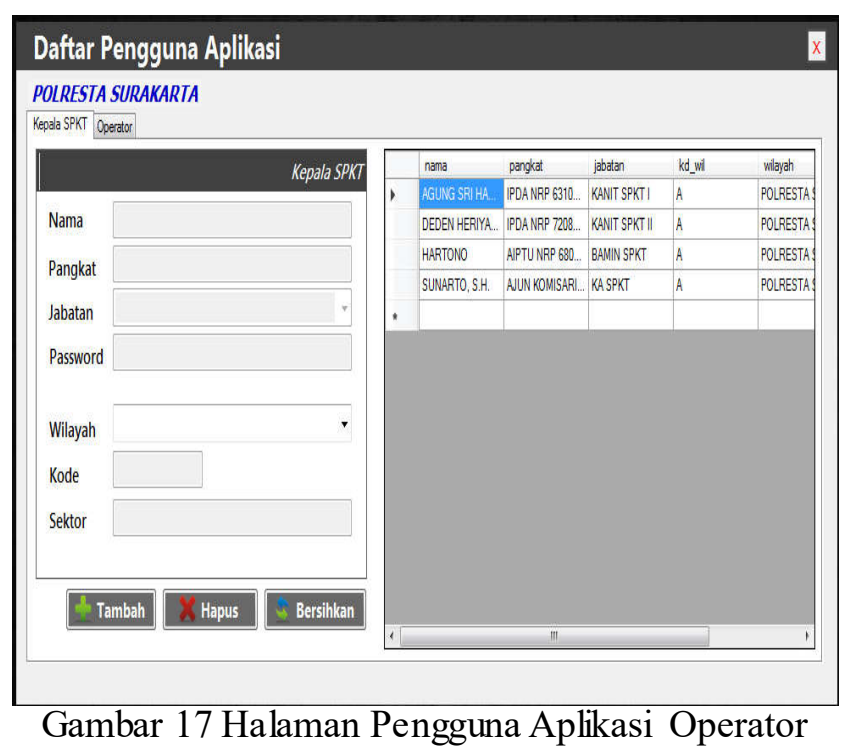

Halaman operator seperti Gambar 17 berfungsi untuk membuat dan mengelola user atau operator penerima laporan. Nama Kepala SPKT dan operator akan otomatis muncul pada saat mencetak laporan.

\subsubsection{Pemeliharaan Sistem}

Pemeliharaan sistem dilakukan untuk menghindari masalah-masalah yang menyebabkan sistem tidak dapat berjalan dengan normal, seperti serangan virus komputer, kesalahan data akibat bug program, hilangnya data pada database, dan kerusakan hardware. Dengan adanya pemeliharaan maka sistem dapat dikontrol, sehingga ketika dioperasikan tidak akan mengalami hambatan dan menemui masalah. Kegiatan pemeliharaan sistem tersebut meliputi:

1) Memberi pelatihan kepada personil yang akan mengoperasikan sistem dengan memberikan pemahaman cara mengatasi jika terjadi error dan mencatat error tersebut untuk diperbaiki. 
2) Melakukan perbaikan jika saat penggunaan terjadi kesalahan (bugs) pada program atau kelemahan rancangan, yang tidak terdeteksi saat tahap pengujian sistem.

3) Melakukan pembaruan sistem jika ada pembaruan dan perubahan pada jenis data atau isian laporan maupun perubahan yang lainnya.

\subsubsection{Pembahasan}

Pengelolaan administrasi yang dilakukan pada jajaran Polsek di Polresta Surakarta sebelumnya masih mempunyai banyak kelemahan seperti yang penulis uraikan pada analisis kelemahan sistem. Dengan adanya kelemahantersebut, penulis membuat Sistem Informasi Pelayanan di Sentra Pelayanan Kepolisian Terpadu (SPKT) Jajaran Polsek di Polresta Surakarta, dan dapat menghasilkan keunggulan antara lain:

1. Performance, Otomatisasi dalam pemberian nomor register dapat mempercepat petugas dalam membuat suatu laporan dan menghilangkan adanya kemungkinan nomor ganda maupun terlewatkan. Operator atau petugas tidak melakukan pengetikan yang berulangulang, karena sistem sudah bisa membaca, memilah dan mengolah data yang ada.

2. Information, Dengan adanya database digital, maka dapat memback up arsip hardcopy yang ada.

3. Economic, Petugas di Polresta Surakarta dapat melihat dan merekap di semua jajaran Polsek maupun Polresta Surakarta dengan adnya sistem, sehingga dapat lebih efisien dimana sistem yang lama memerlukan waktu dan tenaga.

4. Control, keamanan data dan informasi akan menjadi lebih baik, dengan adanya database digital. Polresta Surakarta juga dapat melihat sejauh mana kinerja dari Polsek di jajarannya dengan cepat dan tepat.

5. Efficiency, engan sistem yang baru maka akan di dapat efisiensi dalam hal waktu, baik waktu pengerjaan, waktu penyampaian informasi, maupun dalam perekanapn laporan atau kejadian.

6. Service, dengan adanya sistem ini pelayanan kepada masyarakat akan lebih meningkat atau cepat, dan pelayanana kepada pimpinan tentang penyajian data akan lebih cepat, sehingga pimpinan dapat membuat keputusan atau kebijakan yang tepat.

\section{KESIMPULAN}

Berdasarkan penelitian yang dilakukan pada Jajaran Polsek Polresta Surakarta mengenai sistem informasi administrasi Sentra Pelayanan Kepolisian di Jajaran Polsek Polresta Surakarta, dapat diambil kesimpulan bahwa:

1. Perancangan sistem menggunakan pemodelan UML (Unified Modeling Language) dengan komponen yang digunakan yaitu use case diagram, class diagram, activity diagram, Sequence diagram dan desain interface. Sistem dibangun menggunakan bahasa pemrograman Visual basic .NET 2013 dan database menggunakan MySql. Sehingga menghasilkan Sistem Informasi Pelayanan di Sentra Pelayanan Kepolisian Terpadu (SPKT) Jajaran Polsek di Polresta Surakarta, dengan databasenya secara online atau menggunakan hosting.

2. Hasil pengujian perangkat lunak pada pembangunan Sistem Informasi Sentra Pelayanan Kepolisian di Jajaran Polsek Polresta Surakarta menyatakan semua butir uji pada kelas uji dan tingkat pengujian sistem dengan teknik pengujian blackbox menguji semua fungsionalitas aplikasi dari Sistem Informasi Simpan Pinjam dinyatakan diterima dan telah terukur.

3. Dengan adanya Sistem Informasi Sentra Pelayanan Kepolisian di Jajaran Polsek Polresta Surakarta akan memberikan kemudahan dalam pencatatan data, pengolahan data, pembuatan laporan dan dalam pengarsipan dokumen data, diharapkan dapat memaksimalkan kinerja anggota Kepolisian yang selama ini mengalami beberapa kendala. 
4. Dengan bertambah cepat dan mudahnya pembuatan laporan polisi menggunakan Sistem ini, diharpkan pelayanan Polri terhadap masyarakat dapat meningkat dan di percaya oleh masyarakat. Untuk pimpinan Polri juga dapat mendapatkan informasi atau data yang lebih cepat sehingga dalam mengambil kebijakan atau keputusan akan lebih baik

\section{SARAN}

Saran yang penulis ajukan demi pengembangan dan implementasi Sistem Informasi Sentra Pelayanan Kepolisian di Jajaran Polsek Polresta Surakarta di masa mendatang adalah sebagai berikut :

1. Sistem Sistem Informasi Sentra Pelayanan Kepolisian di Polresta Surakarta ini dapat terhubung dengan fungsi lain yang terkait, seperti Reserse sehingga perkembangan kasusnya dapat terlihat dan termonitor secara jelas.

2. Sistem Sistem Informasi Sentra Pelayanan Kepolisian di Polresta Surakarta ini dapat ditambah dengan hasil data-data dari Satuan Lalu Lintas, seperti data kecelakaan, data pelanggaran, dll.

3. Sistem Informasi Sentra Pelayanan Kepolisian di Jajaran Polsek Polresta Surakarta ini dapat di gunakan di banyak Polres ataupun satuan Polri diatasnya, sehingga dapat bersinergi dari tingkat atas hingga bawah.

\section{DAFTAR PUSTAKA}

[1] Adelia, Setiawan J. 2011. Implementasi Customer Relationship Management (CRM) pada Sistem Reservasi Hotel berbasisi Website dan Desktop. Bandung: Universitas Kristen Maranatha.

[2] Dwiyanto, Agus. 2006. Reformasi Birokrasi Publik. Yogyakarta Gadjah Mada University Press.

[3] Gottschalk, Louis. 1986. Mengerti Sejarah, Nugroho Notosusanto, Jakarta:UI Press .

[4] Huo, M., Verner, J., Zhu, L., Babar, M.A. 2004 "Software Quality and Agile Methods", Proceedings of the 28th Annual International COMPSAC.

[5] Khalaf, S.J., Al-Jedaiah, M.N. 2008 "Software Quality and Assurance in Waterfall model and XP - A Comparative Study",

[6] Kitab Undang-undang Hukum Acara Pidana (KUHAP)

[7] Peraturan Kepala Kepolisian RI No. 12 Tahun 2009 tentang Pengawasan Dan Pengendalian Penanganan Perkara Pidana Di Lingkungan POLRI

[8] Petersen, K., Wohlin, C., Baca, D. 2009 "The Waterfall Model in Large-Scale Development", Proceedings of 10th International Conference, PROFES.

[9] Pressman, R.S.2010 Software Engineering: a Practioner's Approach 7th Edition, McGraw-Hill Higher Education.

[10] Ragil, Wukil. 2010. Pedoman Sosialisai Prosedur Operasi Standar. Mitra Wacana Media. Jakarta.

[11] Raharjo, Budi.2011. "Membuat Database Menggunakan MySql". Bandung : Informatika.

[12] Sommerville, Ian. 2011. Software Engineering (Rekayasa Perangkat Lunak). Jakarta: Erlangga.

[13] Sugiyono. 2009 Metode Penelitian Kuantitatif dan Kualitatif. CV.Alfabeta: Bandung.

[14] Supardi, M.d, 2006. Metodologi Penelitian. Mataram: Yayasan Cerdas Press.

[15] Sutopo, HB. 2006, Metode Penelitian Kualitatif, Surakarta: UNS Press.

[16] Undang Undang No. 02 Tahun 2002 tentang Kepolisian Negara Republik Indonesia.

[17] Undang Undang No. 25 Tahun 2009 tentang Pelayanan Publik.

[18] Usman dan Akbar. 2000. Pengantar Statistika. Jakarta: Bumi Aksara. 